WellBeing International

WBI Studies Repository

4-1989

\title{
Specificity of the Cardiac Response to Conspecific Vocalizations in Chimpanzees
}

Gary G. Berntson

Ohio State University

Sarah T. Boysen

Ohio State University

Follow this and additional works at: https://www.wellbeingintlstudiesrepository.org/acwp_asie

Part of the Animal Structures Commons, Animal Studies Commons, and the Other Animal Sciences

Commons

\section{Recommended Citation}

Berntson, G. G., \& Boysen, S. T. (1989). Specificity of the cardiac response to conspecific vocalizations in chimpanzees. Behavioral neuroscience, 103(2), 235.

This material is brought to you for free and open access by WellBeing International. It has been accepted for inclusion by an authorized administrator of the WBI Studies Repository. For more information, please contact wbisr-info@wellbeingintl.org.

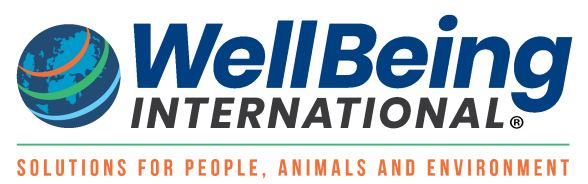




\title{
Specificity of the Cardiac Response to Conspecific Vocalizations in Chimpanzees
}

\author{
Gary G. Berntson ${ }^{1,2}$ and Sarah T. Boysen ${ }^{1,2}$ \\ ${ }^{1}$ Ohio State University \\ ${ }^{2}$ Emory University
}

\begin{abstract}
Heart rate measures were used to examine the functional response of young chimpanzees and orangutans to acoustic stimuli, including white noise and chimpanzee vocalizations (threat, stress, and alarm). The initial response of the animals to all stimuli was characterized by a prominent cardiac deceleration and an increase in heart period variability. The deceleratory responses persisted with repeated presentations of the noise, stress, and alarm stimuli. In contrast, the response of chimpanzees to the conspecific threat stimulus reverted over trials to a notable cardiac acceleration. This acceleratory response was not attributable to potential patterns of evoked somatic responses. The features of the cardiac response, together with the results of frequencydomain analyses of heart period variability, suggest that this acceleratory response was consistent with the evocation of an aversive or a defensive reaction characterized by sympathetic activation. This pattern of cardiac response appeared early in ontogeny (within $48 \mathrm{hr}$ postnatally) and was not manifest in orangutans. Taken together, the results suggest the existence of specialized perceptual processing mechanisms for vocal stimuli in the chimpanzee. Further examination of these mechanisms may contribute to our understanding of central perceptual processes and the evolution of vocal communication.
\end{abstract}

It is becoming increasingly apparent that primate vocal communications share many common features with human speech. In contrast to the view that primate vocalizations are fundamentally egocentric, relating simply to internal states or courses of action, recent studies have demonstrated that primate utterances can evidence communicative intentionality (Dennett, 1983), convey specific information concerning environmental referents (Seyfarth \& Cheney, 1984), and display a syntactical organization (Snowdon, 1982). Furthermore, the acoustic perception of primates evidences features similar to those that underlie speech processing in humans (Liberman, Cooper, Shankweiler, \& Studdert-Kennedy, 1967). Among these features is the categorical perception of graded phonemes, for which primates demonstrate perceptual boundaries largely indistinguishable from those of humans (Kuhl, 1987b; Petersen, 1982; Snowdon, 1982). A second feature, also evidenced in primates, is the lateralized hemispheric processing of specific vocal signals (Morse, Molfese, Laughlin, Linnville, \& Wetzel, 1987; Petersen, 1982; Petersen et al., 1984; Pohl, 1983). Although these features may not be unique to speech perception (Kuhl, 1987b; Pisoni, 1987), they suggest the existence of at least partially overlapping modes of processing for vocal signals in humans and nonhuman primates. In view of these considerations, a further understanding of 
vocal processing in nonhuman primates may not only enhance our appreciation of vocal communication in these species but also contribute to our understanding of the evolution of language processes.

Previous studies have shown that nonhuman primates can (a) discriminate conspecific from contraspecific vocalizations (Petersen, 1982; Petersen et al., 1984); (b) differentially respond to different classes, or variations within a class, of vocalization (Green, 1975; Seyfarth \& Cheney, 1984); and (c) recognize individuals on the basis of their vocal signals (Cheney \& Seyfarth, 1980; Marler \& Tenaza, 1977; Snowdon \& Cleveland, 1980). Although to an appreciable extent, these capabilities may be attributable to social learning processes (DeCasper \& Fifer, 1980; DeCasper \& Spence, 1986; Newman \& Symmes, 1982; Snowdon, 1982), certain aspects of the perceptual response to conspecific vocalizations may be constitutionally predisposed (Newman \& Symmes, 1982; Nottebohm, 1984; Nottebohm, Nottebohm, \& Crane, 1986; Seyfarth \& Cheney, 1984). One approach to this question is through an examination of the ontogeny of vocal perception. A considerable literature on the ontogeny of acoustic perception in humans documents an early appearance of selective processing mechanisms for vocal stimuli in infants (Aslin, Pisoni, \& Jusczyk, 1983; Kuhl, 1987a; Molfese, 1987; Trehub, 1987). Unfortunately, considerably less is known concerning the ontogeny of perceptual processing of vocal stimuli in nonhuman primates.

A notable impediment to ontogenetic studies of vocal perception is the limited behavioral repertoire of infant primates. One approach to this problem in humans has been the application of psychophysiological measures of autonomic response or cerebral electrical activity, which has proven highly useful for the study of cognitive processes in the infant (Berg \& Smith, 1983; Berntson, Tuber, Ronca, \& Bachman, 1983; Molfese, 1987; Morrongiello \& Clifton, 1984). In the present study, we employed heart rate indexes to examine the functional response of young chimpanzees to conspecific vocalizations. Heart rate measures are readily obtained in this species and have been shown to be highly sensitive to patterns of behavioral response (Berntson \& Boysen, 1987; Boysen \& Berntson, 1986). From an evolutionary perspective, the chimpanzee represents an ideal model for such an inquiry. Chimpanzees appear to be the closest extant relatives of humans, and current estimates suggest that the vast preponderance of their genetic material is shared in common with that of humans (Goldman, Giri, \& O'Brien, 1987; Goodman, Braunitzer, Stangl, \& Schrank, 1983). In addition, LeMay and Geschwind (1975) and Yeni-Komshian and Benson (1976) suggested that the great apes may evidence lateralized enlargement of cortical areas corresponding to those that have been implicated in language functions in humans. We here report that a distinct pattern of cardiac response is evoked by conspecific threat vocalizations in the chimpanzee. This selective response emerges very early in postnatal development, is not elicited by other vocalizations, and is not apparent in another ape species, the orangutan.

\section{Method}

\section{Subjects}

Subjects were 6 captive-born chimpanzees ( 4 male and 2 female) and 3 orangutans ( 2 male and 1 female). Chimpanzees ranged in age from $48 \mathrm{hr}$ to 2.9 years, and orangutans were 2.4-5.0 months old. Five of the chimpanzees and the orangutans were from the collection at the Yerkes Regional Primate Research Center (Emory University, Atlanta, Georgia), and 1 chimpanzee was a participant of the Primate Cognition Project at Ohio State University. For a variety of reasons, including illness of the mother or inadequate maternal care, the 8 Yerkes animals had been separated from their mothers at, or shortly after, birth. They had thereafter been raised in the nursery with peers. The final animal was separated from its mother at 4 months of age and was home reared for about 2 years prior to joining our project. 


\section{Electrocardiographs (ECG) Recordings}

Heart rate was measured by disposable silver/silver chloride surface electrodes secured at thoracic monitor sites V6 and A2, with A1 serving as ground. Electrodes were connected to an ERM 101 cardiotachometer, and the ECG signal was simultaneously recorded on a Cardiodyne FM tape recorder for off-line playback on a Grass Model 7 polygraph. The pulse output of the cardiotach R-wave detector was coupled to a 6502 microcomputer interface for on-line determination of individual heart periods (interbeat intervals). Heart period values for $5 \mathrm{~s}$ before and $15 \mathrm{~s}$ after each stimulus were stored for subsequent analysis. Potential artifacts in the ECG record were identified off-line by the computer system as heart periods that deviated from surrounding values by more than $35 \%$. These values were verified or corrected by direct measurement from the polygraph record. In addition to the beat-by-beat measures, individual heart periods were assigned to 1-s peristimulus time bins, the mean heart period was calculated for each second, and these values were converted to second-by-second rate measures. Trials were excluded from analysis if (a) the mean or variance of the 5-s prestimulus heart rate values was more than 2.5 standard deviations from the session mean for that animal, (b) if the prestimulus heart rate displayed a linear trend of greater than 20 beats per-minute, or (c) if notable somatic movements were observed in the prestimulus period. These criteria collectively resulted in the elimination of less than 10\% of the trials.

\section{Auditory Stimuli}

All animals were tested for cardiac reactivity to four auditory stimuli, each having an overall envelope duration of approximately 1,000 ms and a peak intensity of $78 \mathrm{~dB}(\mathrm{SPL})$. Stimuli included a white noise control stimulus and three chimpanzee vocalizations. The vocalizations were obtained from captive-born animals of the Primate Cognition Project during actual social encounters. (With the exception of the oldest subject, these animals had never had contact with the experimental subjects.) Vocalization stimuli included threat barks, stress screams, and alarm calls. All stimuli were recorded on tape (filtered at 4 $\mathrm{kHz})$, computer digitized $(8 \mathrm{kHz})$, and matched for intensity and duration of the stimulus envelope. White noise was derived from a broadband noise generator, and the vocalization stimuli were obtained from animals of the Primate Cognition Project. The threat vocalization consisted of a series of guttural barks, alarm comprised higher pitched hoo-like calls, and the stress vocalization was a relatively continuous scream. These vocalizations corresponded in character, and the context in which they were emitted, to the bark (Marler \& Tenaza, 1977), hoo (van-Lawick Goodall, 1968), and scream (Marler \& Tenaza, 1977; van Lawick-Goodall, 1968) vocalizations, as previously described for the common chimpanzee.

\section{Procedure}

All testing was completed in an isolated room, with the subjects in a quiet wakeful state. Younger animals were recumbent in an isolette, and older animals were tested while sitting quietly. After attachment of ECG electrodes, the test room was darkened (10 Ix), and animals were given a period of adaptation. Adaptation was continued until the animal became behaviorally quiescent, and considerable care was taken to ensure that all animals were relaxed and complacent in the experimental environment. All testing was completed after feeding in order to minimize behavioral activity. No artificial restraints were employed, but care was taken to ensure that a given animal maintained the same postural configuration throughout the test session. If the subject moved or became active, testing was momentarily suspended, and the animal was repositioned. Subjects received six trials with each of the four stimuli, which were presented in a block randomized sequence with a variable $40-\mathrm{s}$ interstimulus interval (30-50 s). Stimuli were presented via a midline free-field speaker, to avoid potential behavioral disquietude associated with the use of headphones. All stimuli yielded an intensity of $78 \mathrm{~dB}(\mathrm{SPL})$ at the subject plane. Heart rate was recorded continuously for $5 \mathrm{~s}$ before and $15 \mathrm{~s}$ after each stimulus, according to the procedures outlined 
above. In addition, the behavioral response of the animal to each stimulus was categorized as follows: (a) startle, (b) nonstartle movement, or (c) no observable response. Startle responses were denned as any short-latency impulsive movements (generally Moro-like responses), and other patterns of somatic response were considered nonstartle movements. The latter usually consisted of slow arm or leg movements or general increases in activity. All behavioral categorizations were made on-line, without knowledge of the corresponding evoked cardiac response.

\section{Data Analysis}

Acoustic stimuli. In order to directly evaluate the characteristics of the stimuli as delivered to the subjects, the speaker output was computer digitized at $12 \mathrm{kHz}$. The amplitude envelope of each stimulus was derived from the digitized data, and spectral compositions were determined by a discrete Fourier transform (Cooley \& Tukey, 1965). In order to minimize harmonic leakage and distortion, data were first filtered to remove DC components, and then tapered by a modified Hanning window (20\% split-bell cosine taper; Bloomfield, 1976).

Cardiac responses. The principal analysis of the heart rate data was by analysis of variance on the poststimulus cardiac response, according to a 4 (vocalization) $\times 3$ (5-s poststimulus time bins) $\times 2$ (threetrial blocks) repeated measures design. The latter factor was included because our previous studies of nonsignal stimuli had revealed changes in the cardiac response over trials (Berntson \& Boysen, 1984). Post hoc comparisons were based on the Tukey test.

For some animals, cardiac responses comprised a mixture of acceleratory and deceleratory components. Under these conditions, mean values averaged across animals or trials may not adequately characterize individual responses. Consequently, we also analyzed acceleratory and deceleratory response components separately. For these analyses, the integral area under the poststimulus cardiac responsetime function was determined independently for acceleratory and deceleratory components in each animal. The relative proportions of acceleratory and deceleratory responses were evaluated by analysis of variance, according to a 4 (stimulus) $\times 2$ (trial blocks) design.

Beat-by-beat heart period variability was examined by the successive difference mean square statistic of Heslegrave, Ogilvie, and Furedy (1979). This measure was selected because it is minimally contaminated by the presence of phasic heart rate responses. The variability indexes were evaluated by analysis of variance, as described above for heart rate data. Because heart period variability can arise from multiple sources, we further analyzed beat-by-beat variability in the frequency domain. Of particular interest in this analysis was a component of variability associated with respiratory sinus arrhythmia (RSA). The magnitude of RSA has been suggested to provide a reliable index of fluctuations in vagal tone (McCabe, Yongue, Ackless, \& Porges, 1985; Porges, McCabe, \& Yongue, 1982). The present analysis was performed according to the general methods outlined in the above studies. Heart period values were derived at fixed intervals $(250 \mathrm{~ms})$ for $1 \mathrm{~s}$ before and $15 \mathrm{~s}$ after each stimulus, by a weighted mean of individual heart periods falling wholly or partially within each interval. Trial-by-trial data were then lowfrequency filtered (at $0.06 \mathrm{~Hz}$ ) by a third degree polynomial. This served to minimize contamination from slow phasic heart rate responses to the stimuli, and to achieve stationarity of the time series (constant mean and variance), as necessary for the spectral analysis. In order to minimize harmonic leakage from strong frequency peaks, the data were tapered with a modified Hanning window (20\% split-bell cosine taper; Bloomfield, 1976). The data were then submitted to a 64-point discrete Fourier transform (DFT), by using the Cooley-Tukey algorithm (Cooley \& Tukey, 1965). A measure of RSA was derived as the integral area under the DFT function for frequency values from 0.1 to $1.0 \mathrm{~Hz}$. This range has been previously employed with animals (McCabe et al., 1985) and was sufficiently wide to encompass within- and 
between-animals variations in respiratory rate in the present study. The log transform of these integrals was then derived, and these values were evaluated by analysis of variance.

Behavioral responses. Data on evoked somatic responses to the experimental stimuli were collated, and the probability of responses to different stimuli evaluated by the chi-square test for goodness of fit. To explore the relation between cardiac and behavioral responses, we also analyzed cardiac responses according to trial groupings based on the evoked somatic response (startle, nonstartle movement, or no response). Because no movement was apparent during most trials, this procedure yielded widely disparate numbers of trial across the somatic response categories. In view of this consideration, and because trials were grouped on the basis of a response outcome, these data are used primarily for illustration, and statistical analyses were based on nonparametric methods (Friedman's test).

\section{Results}

\section{Vocalization Stimuli}

Analyses of the experimental stimuli are illustrated in Figure 1, which shows the amplitude envelope and spectral composition of each of the acoustic stimuli. Differences in the acoustic envelopes are apparent, with the noise and stress vocalizations being relatively continuous throughout the stimulus interval. In contrast, the threat and alarm stimuli were more pulsatile, both peaking in the last half of the stimulus period. As is apparent from the figure, the white noise stimulus was relatively broadband. In contrast, the energy of the stress scream was concentrated at the higher frequencies, whereas both the threat and alarm stimuli were characterized by lower frequency components. The principal difference between the latter two stimuli was an additional low-frequency peak of the threat vocalization (at approximately 450 $\mathrm{Hz})$.

\section{Heart Rate Responses}

As illustrated in Figure 2, the overall cardiac responses to the white noise, stress, and alarm vocalizations were predominately deceleratory, whereas a notable acceleration was seen to the threat vocalization. Heart rate responses were evaluated by a repeated measures analysis of variance, according to a 4 (stimulus type) $\times 3$ (5-s poststimulus time bins) $\times 2$ (three-trial blocks) design. Data contributing to this analysis are illustrated in Figure 3. As is apparent, the initial response to each stimulus (first three trials) was characterized by cardiac deceleration, sometimes preceded by a transient acceleration. In the second block of trials, however, the response to threat was characterized by a dramatic and long-lasting cardiac acceleration, but responses to other stimuli continued to be primarily deceleratory. Although baseline (prestimulus) heart rates did not differ among the stimuli (noise $=142.9$, threat $=142.2$, stress $=$ 143.0, alarm = 143.1), $F(3,15)<1$, significant differences were apparent in the poststimulus cardiac responses. The analysis of variance on the poststimulus heart rate response revealed a significant overall effect of stimulus type, $F(3,15)=3.64, p<.04$, which largely reflected the distinct acceleratory response pattern to the threat stimuli. A Trial Block $\times$ Stimulus Type interaction, $F(3,15)=5.86, p<.01$, was further indicative of the increase over trials in this acceleratory response to threat stimuli. Post hoc comparisons (Tukey test) revealed that the cardiac response to threat vocalization in the second block of trials was significantly more acceleratory than the response to any other stimulus, and to the response during the first three presentations of the threat stimulus. Responses to the remaining stimuli did not differ among themselves or from the first to the second block of trials.

Component analysis. Because cardiac responses sometimes evidenced both acceleratory and deceleratory components, data averaged across animals or trials could obscure the pattern of evoked cardiac response on individual trials. Consequently, we specifically analyzed acceleratory and decelerator 
response components. Integral areas of the poststimulus cardiac response-time function were determined separately for the acceleratory and deceleratory response components for each animal and each stimulus modality. These data (illustrated in Figure 4) were evaluated by an analysis of variance on the relative proportion of acceleratory and deceleratory components in the overall cardiac response. This analysis revealed a significant interaction between stimulus type and trial blocks, $F(3,15)=6.29, p<.01$. Post hoc analyses indicated that the proportion of acceleratory components to threat in the second block of trials was significantly greater than for the first block, and greater than for any other stimulus. As illustrated in Figure 4, this effect was related to both an increase in acceleratory components and a decrease in deceleratory response components to the threat stimulus over trials.

Figure 1. Amplitude envelopes and spectral compositions of the acoustic stimuli.

Amplitude Envelope
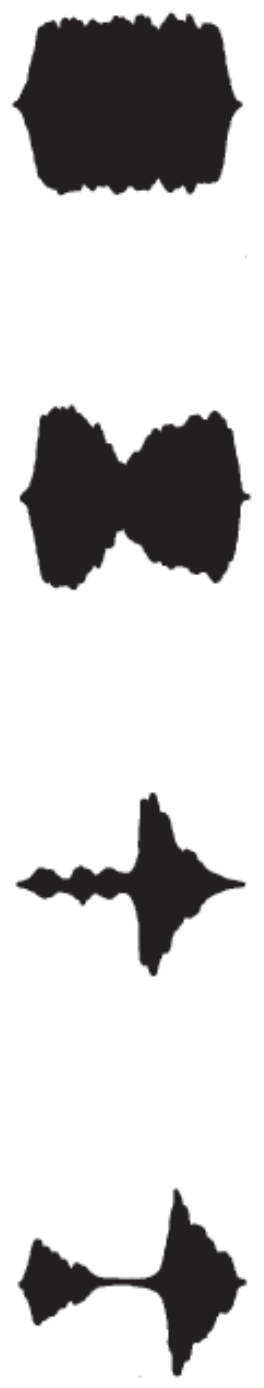

$1 \mathrm{Sec}$
Noise

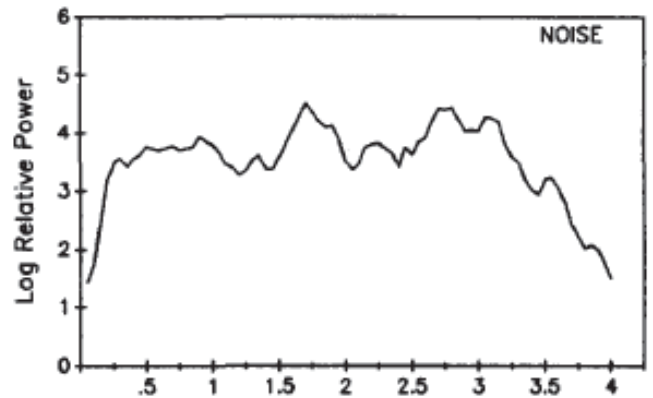

Stress

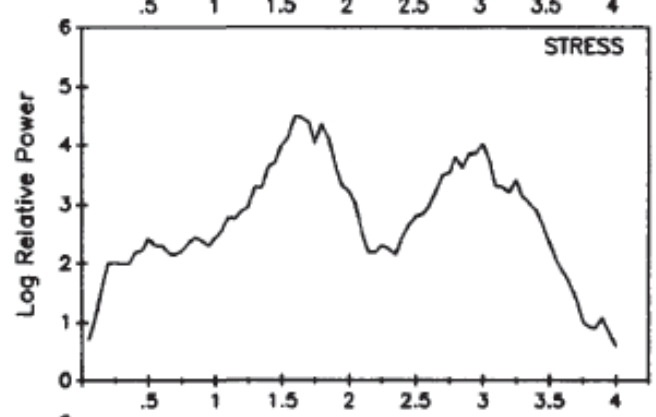

Threat

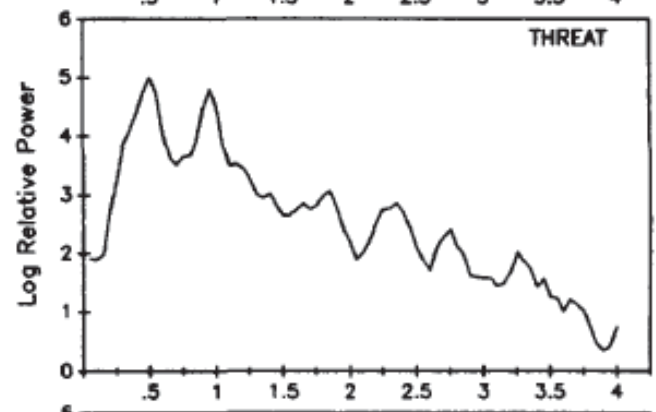

Alarm

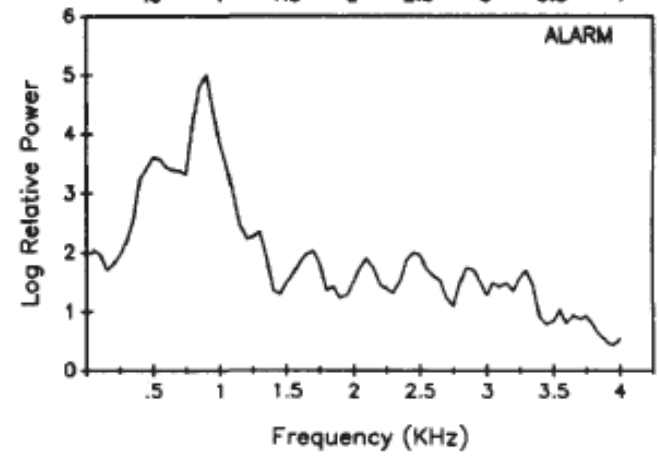


Figure 2. Heart rate (HR) response of chimpanzees and orangutans to acoustic stimuli, averaged over the six presentations of each stimulus. (Stimulus presentation was at Time 0. BPM = beats per minute.)
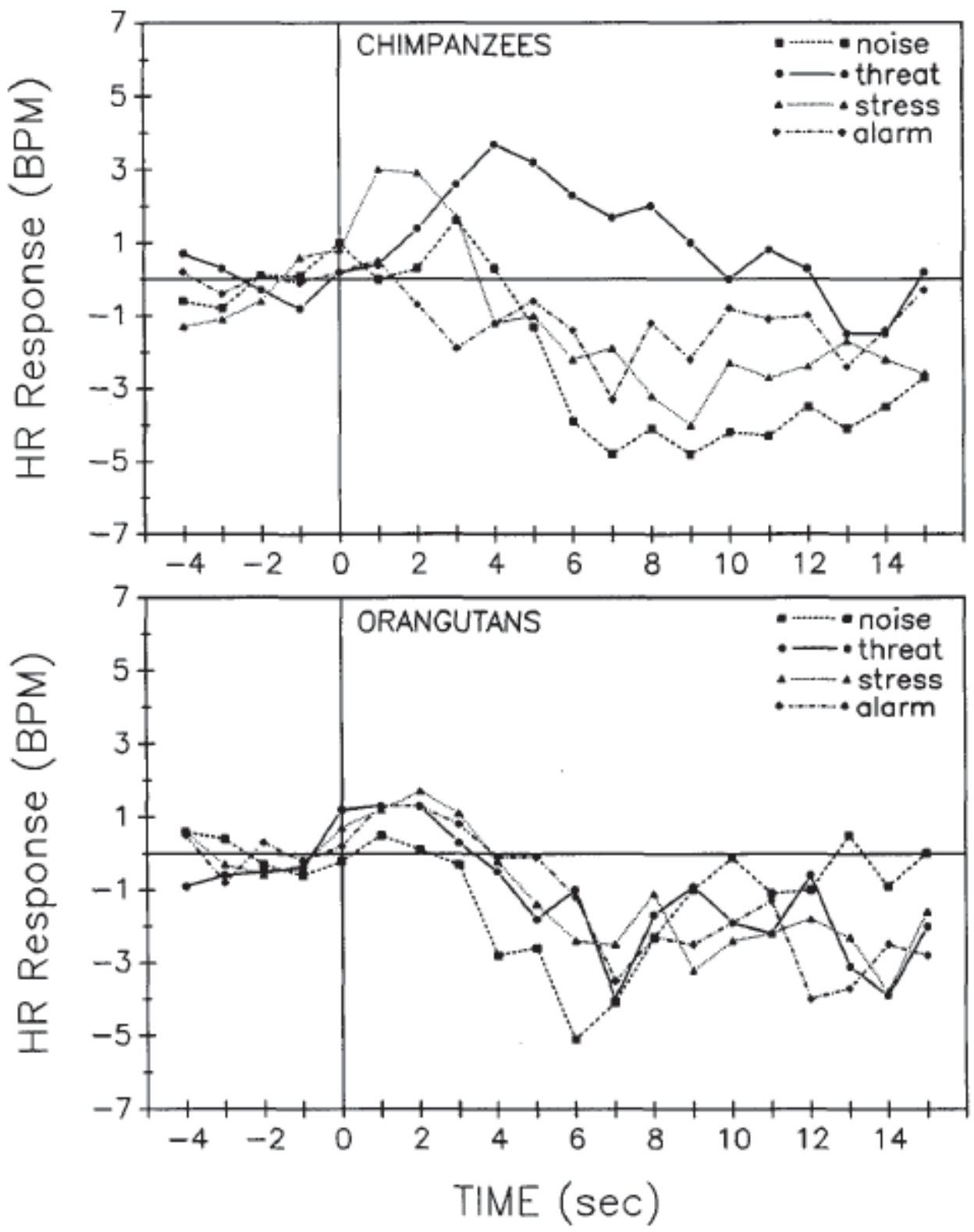

\section{Heart Period Variability}

Heart period variability, as indexed by the successive difference mean square statistic of Heslegrave et al. (1979), was increased by all classes of stimuli. These data were evaluated by a repeated measures analysis of variance according to a 4 (stimulus type) $\times 4$ (one pre and three poststimulus 5 -s time periods) $\times 2$ (trial blocks) design. A significant main effect of time period, $F(3,15)=4.64, p<.02$, reflected the stimulus-induced increment in variability (mean variability during the prestimulus period $=16.2 \pm 1.9$, and during the three poststimulus periods $=21.8 \pm 2.9,18.3 \pm 2.1$, and $18.6 \pm 2.3$, respectively). No significant main effects or interactions were seen for stimulus type or trial block. 
We further found that a component of heart period variability associated with RSA did not differ among the stimuli. The magnitude of RSA was evaluated by a frequency-domain analysis of heart period variability for the 16-s intervals beginning with the last prestimulus second and extending through the 15-s poststimulus period. Results of the discrete Fourier transforms of these heart period values are illustrated in Figure 5. As is apparent, the DFT function peaked at $0.2 \mathrm{~Hz}$ for all stimulus types. As previously employed (McCabe et al., 1985), the log of the integral area under the DFT function extending from 0.1 to $1.0 \mathrm{~Hz}$ was taken as an index of RSA (this spanned the range of respiratory frequencies of the present subjects). Data were evaluated by a 4 (stimulus type) $\times 2$ (trial blocks) analysis of variance, which revealed no significant main effects or interactions.

Figure 3. Heart rate (HR) response of chimpanzees to the acoustic stimuli in the first and second trial blocks. (BPM = beats per minute.)
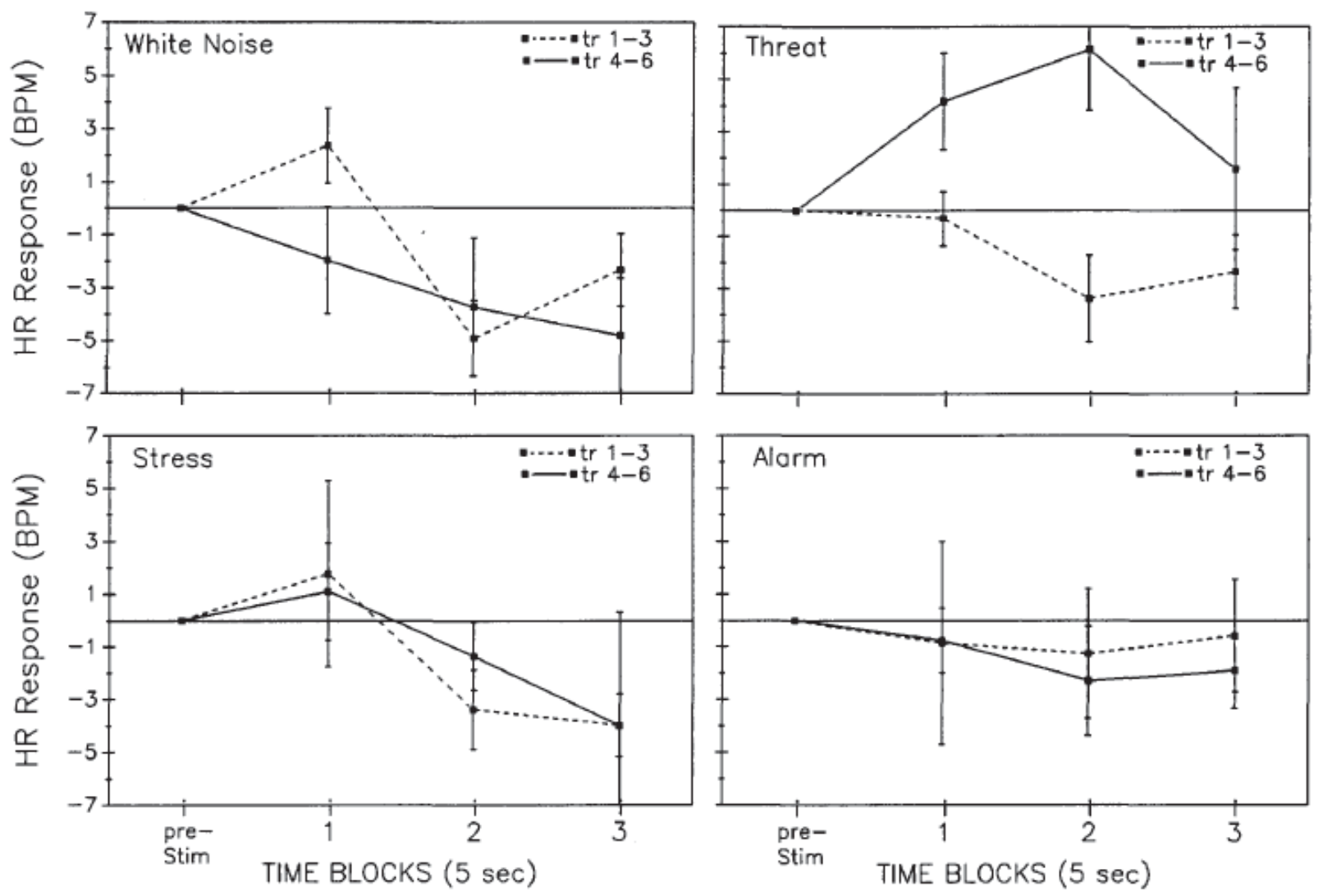

\section{Behavioral Responses}

In a previous study of nonsignal acoustic stimuli in the chimpanzee, we found that startle and nonstartle somatic movements were associated with cardiac acceleration or biphasic acceleratory-deceleratory responses (Berntson \& Boysen, 1984). In the absence of somatic movements, however, the orienting response was characterized by cardiac deceleration. To further explore the relation between cardiac and behavioral responses, we also analyzed somatic responses to the stimuli of the present study. Overall results are illustrated in Table 1 . Only five startle responses were evoked by the 144 stimulus presentations of the present study (three in response to the noise stimulus and two to the alarm vocalization). All startle responses appeared early in the session (within the first trial block). Considerably 
more nonstartle movements were observed. These were also more frequent in the first half of the session, but this difference was not significant, $x^{2}(1, n=26)<1$.

Figure 4. Acceleratory and deceleratory components of the cardiac responses of chimpanzees to the acoustic stimuli. (Integral areas of the acceleratory and deceleratory components were derived separately and plotted as a change from prestimulus baseline. The horizontal dashed lines depict the values expected from the normal heart rate variation observed during the prestimulus period.)

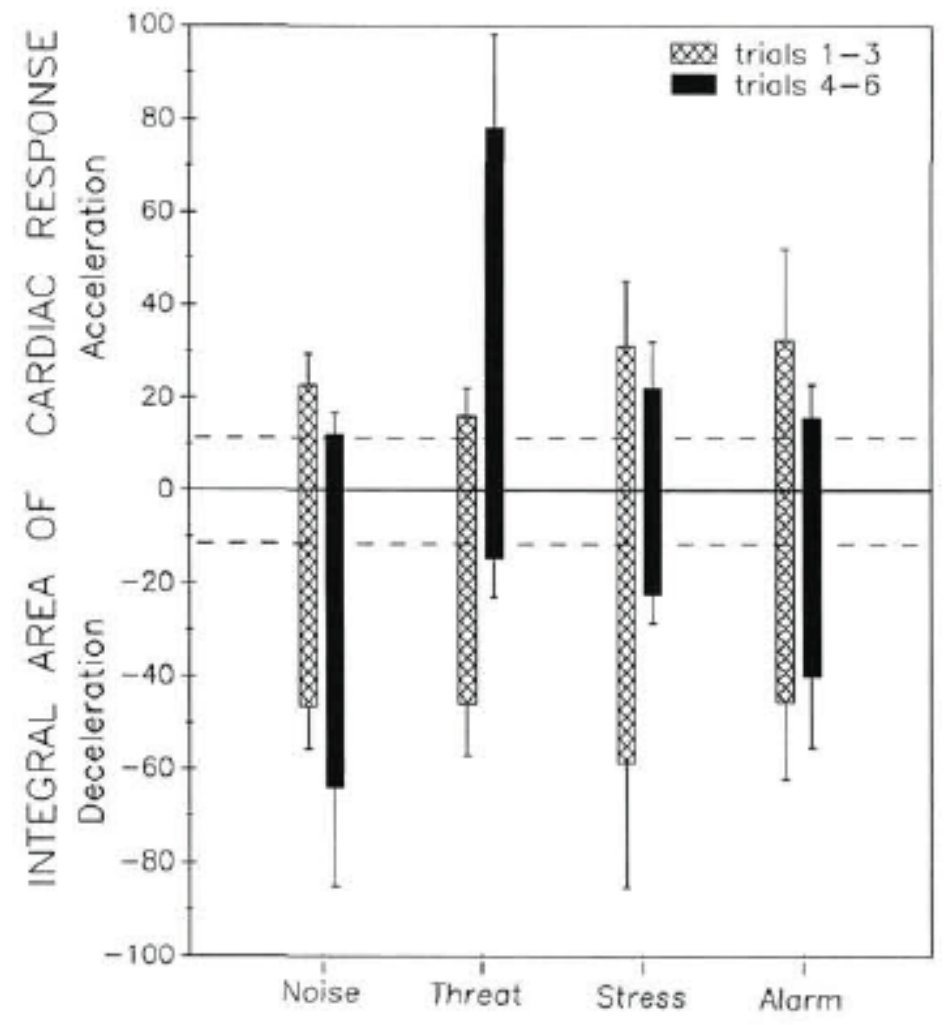

Consistent with our earlier observations, stimulus-induced somatic responses were generally accompanied by acceleratory components to the cardiac response regardless of the evoking stimulus. Figure 6 illustrates the cardiac responses, over all stimulus presentations, that were associated with (a) startle, (b) nonstartle movements, or (c) no somatic response. Because trial groupings were selected on the basis of the elicited behavior, these data were analyzed by nonparametric methods. This analysis revealed significantly greater acceleratory components on trials with evoked somatic movements, relative to trials in which no movement was observed (integral acceleration for trials with somatic responses = $32.4 \pm 14.7$; trials with no somatic response $=11.1 \pm 5.8$ ), Friedman's $x^{2}(1)=6.00, p<.01$. No differences, however, were apparent in the deceleratory components between the somatic response categories (integral deceleration on trials with evoked somatic responses $=30.0 \pm 9.4$; nonresponse trials $=29.2 \pm 13.9), x^{2}(1)<1$.

The cardiac acceleration to threat vocalizations, however, did not appear to be attributable to somatic movements. As described above, the overall cardiac response on trials with no elicited somatic movement was predominately deceleratory. In contrast, cardiac responses to the threat vocalization were predominately acceleratory, even on trials in which no somatic responses were observed (Figure 6). Moreover, these acceleratory responses were not followed by the longer latency deceleratory components that typified movement-related responses. In summary, the cardio-acceleratory responses to 
threat stimuli do not appear to be attributable to somatic movements because (a) somatic responses to the threat stimuli were no more frequent than to other classes of stimuli (Table 1), (b) notable cardiac acceleration to threat was also observed on trials in which no somatic response occurred, and (c) the time course of threat-induced acceleratory responses differed from that associated with movement responses.

Table 1. Probability of a Somatic Response to the Acoustic Stimuli

\begin{tabular}{|lccc|}
\hline Stimulus & Trials 1-3 & Trials 4-6 & Overall $\boldsymbol{M}$ \\
\hline Noise & .33 & .19 & .26 \\
Threat & .28 & .17 & .22 \\
Stress & .28 & .06 & .17 \\
Alarm & .17 & .25 & .21 \\
$M$ & .26 & .17 & .22 \\
\hline
\end{tabular}

Figure 5. Frequency spectrum of poststimulus heart period derived from discrete Fourier transforms. (The vertical lines [0.1 to $1.0 \mathrm{~Hz}$ ] illustrate the frequency window used to derive the index of respiratory sinus arrhythmia.)

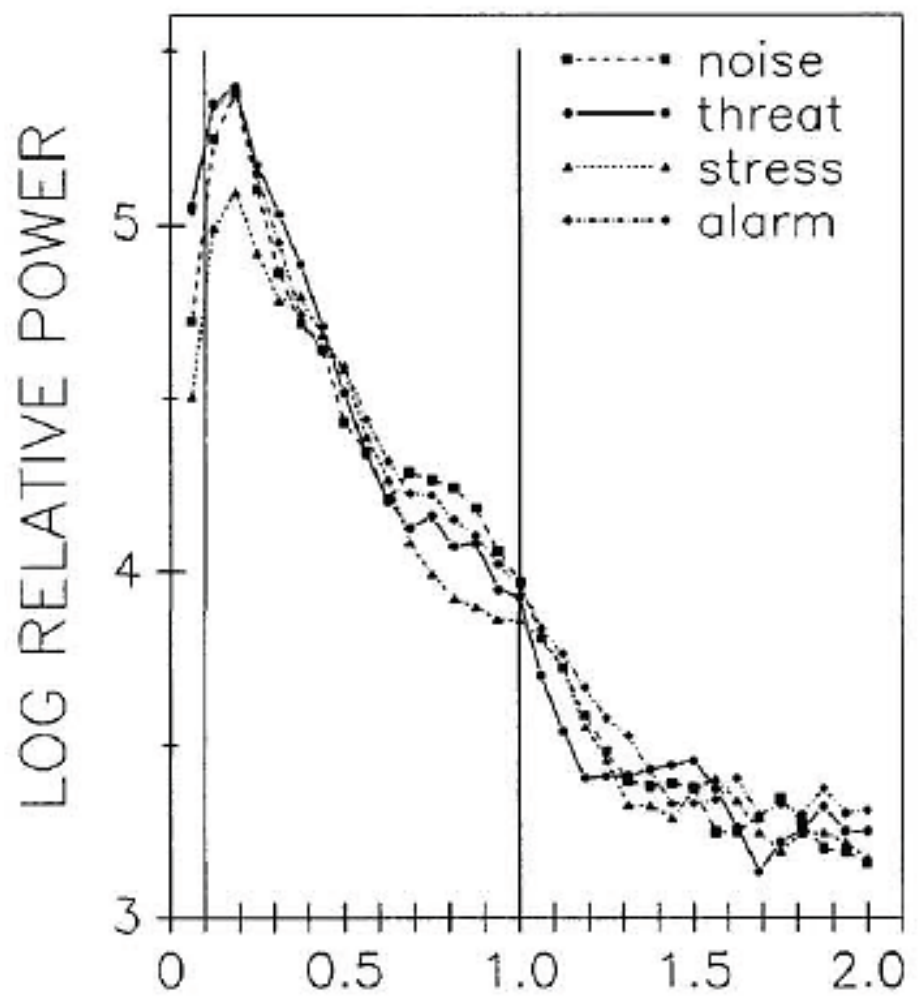

Developmental Features

Baseline heart rate declined somewhat with age, although this relation did not achieve significance in the present group $(r=-.36)$. In addition, age was not significantly correlated with the magnitude of the acceleratory or deceleratory components of the stimulus-induced cardiac responses, either over all stimuli (Age $\times$ Acceleration, $r=$. 12; Age $\times$ Deceleration, $r=-.27$ ) or for threat vocalizations (Age $\times$ Acceleration, 
$r=.08$; Age $\times$ Deceleration, $r=.08$ ). Thus, the cardioacceleratory pattern of response to threat barks did not appear to be age dependent. Indeed, this response was shown by each of the subjects, and the youngest animal (48 $\mathrm{hr}$ ) displayed an acceleratory response to the threat vocalizations that was among the largest observed for all subjects.

\section{Species Differences}

In contrast to the chimpanzees, cardiac responses of infant orangutans were predominately deceleratory to all categories of stimuli (Figure 2). Unfortunately, the small number of available animals (3) precluded parametric analysis as outlined above. Nevertheless, species differences are suggested by these data. The acceleratory responses of each of the 6 chimpanzees were greater for the threat vocalization than for any other stimulus. Moreover, for each chimpanzee, acceleratory components to threat increased more over trials than for any other stimulus. In contrast, neither of these two features characterized the responses of any of the 3 orangutan subjects. Chi-square tests for goodness of fit revealed these outcome distributions to be highly significant, $x^{2}(1, n=9)=7.5, p<.01$. Although considerably more research is necessary to fully characterize potential patterns of species differences, the present data indicate that cardiac acceleration is not an invariable response of all ape species to chimpanzee threat vocalizations.

Figure 6. Top: Heart rate (HR) responses associated with different patterns of evoked somatic response. Bottom: Heart rate responses in the absence of somatic movements, for all stimuli and for threat vocalizations. (BPM = beats per minute.)

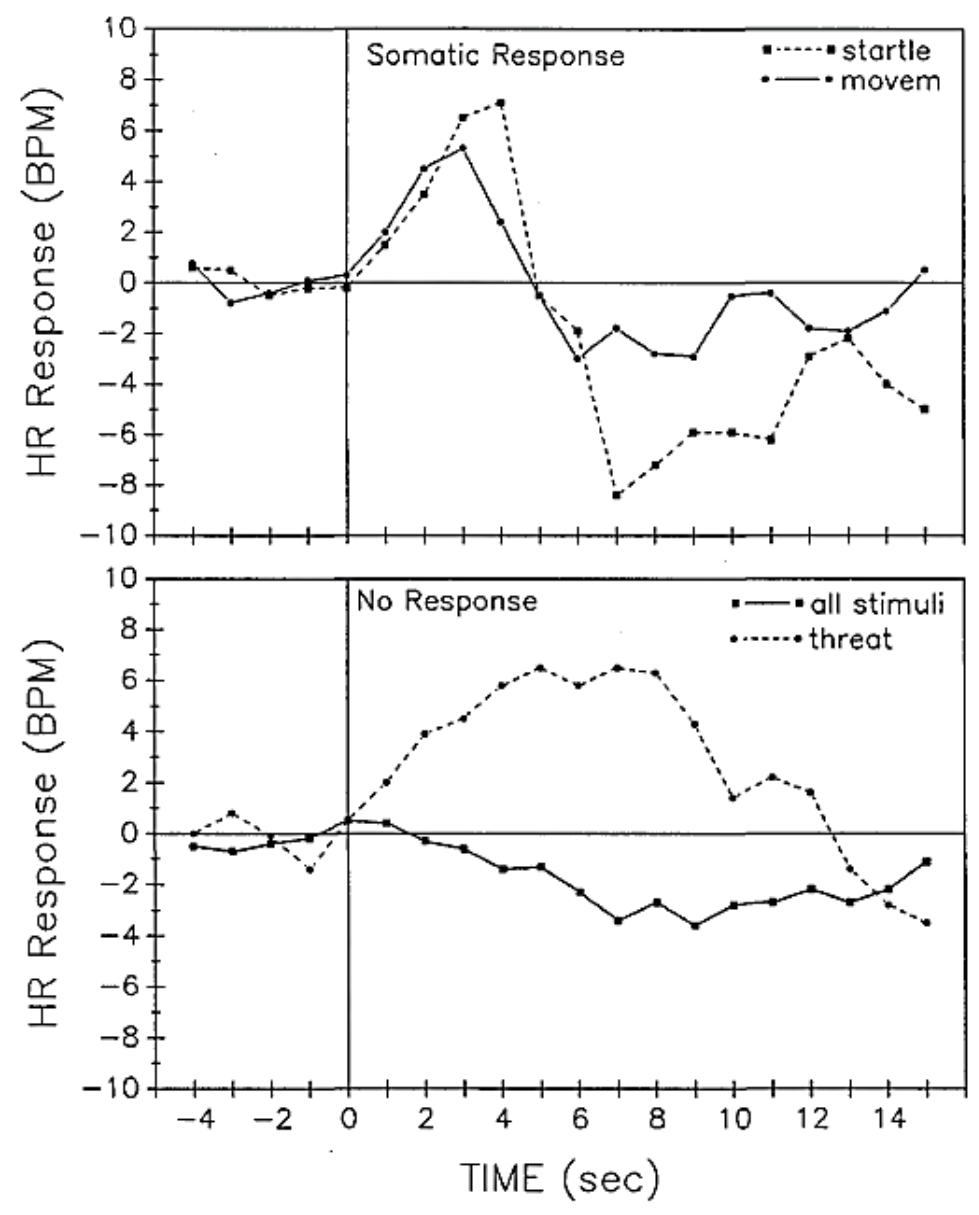




\section{Discussion}

The present results indicate that conspecific threat barks evoke a highly specific pattern of cardiac acceleration in young chimpanzees that differs from the response to white noise or to alarm or stress vocalizations. Initial responses to all stimuli consisted of a prominent cardiac deceleration, characteristic of the orienting response in chimpanzees (Berntson \& Boysen, 1984), monkeys (Weisbard \& Graham, 1971), and humans (Graham, 1979, 1984; Spinks \& Siddle, 1983). This deceleratory response was sometimes preceded by a transient acceleration, which appeared to be associated with somatic startle or movement responses. A similar pattern of cardiac response to vocal stimuli has been reported for birds (Dooling \& Searcy, 1980). Whereas the acceleratory components of the cardiac response to noise, stress, and alarm stimuli tended to decline over trials in the present study, the cardiac acceleration evoked by threat barks significantly increased over trials. This difference did not arise from variations in stimulus intensity, because all stimuli were matched for both intensity and duration of the stimulus envelope. Nor did the difference in cardiac response appear to be associated with the pattern of somatic response to the stimuli, because (a) no differences in somatic response were obtained among the stimuli, (b) somatic responses tended to decline over trials but cardiac acceleration to the threat stimulus increased, and (c) cardiac acceleration was seen to threat even on trials in which no somatic responses occurred.

The functional significance of the cardiac response to threat vocalizations is not entirely clear, although the pattern of increasing acceleration over trials is highly reminiscent of the cardiac component of the defensive response (DR), as described by Graham $(1979,1984)$. Sokolov (1963) initially characterized the DR as a protective reaction against potentially injurious stimuli. After an extensive review of the empirical and theoretical literature, Graham $(1979,1984)$ argued that cardiac DRs are evoked by intense or aversive stimuli and are associated with a long-latency cardiac acceleration (peak $>2 \mathrm{~s}$ ). Moreover, this cardiac acceleration is reported to habituate only slowly, or it may increase over trials (associated with the habituation of a concurrent decelerator orienting response).

Although debate continues on the critical stimulus parameters for the evocation of defensive reactions (Dailey, Wigal, \& Amsel, 1986; Turpin, 1986), the general correspondence between orienting responses and cardiac deceleration, and between aversive reactions and cardiac acceleration, has been well documented (Haroutunian \& Campbell, 1982; Spinks \& Siddle, 1983; Turpin, 1983, 1986). Moreover, in spite of developmental trends in cardiac responses, these general relations also appear to hold for immature organisms (Berg \& Berg, 1979; Graham, Anthony, \& Zeigler, 1983; Larson \& Forges, 1982).

In view of these considerations, the pattern of cardiac response to threat vocalization in the present study is most consistent with the elicitation of a defensive or affective reaction. Additional data are also consistent with this interpretation. Cardiac responses to innocuous stimuli appear primarily to reflect alterations in vagal tone, but responses to aversive or stressful stimuli are often characterized by sympathetic activation (Grossman, 1983; Haroutunian \& Campbell, 1982; Obrist, 1982; Obrist, Wood, \& Perez-Reyes, 1965; Forges et al., 1982). Although cardiac acceleration could result from either an increase in sympathetic activity or a decrease in vagal tone, analysis of RSA suggests that the observed cardiac acceleration in response to the threat vocalization may have been due primarily to sympathetic activation. Because RSA arises largely from reflex modulations of vagal activity, its magnitude has been suggested to provide a relatively pure index of vagal tone (McCabe et al., 1985; Forges et al., 1982; Yongue et al., 1982). Consequently, differential alterations of vagal activity by the vocal stimuli of the present study would be expected to result in differences in the RSA index. In fact, no such differences

were observed. Because vagal tone appears to have been affected similarly by all classes of stimuli, it is likely that the cardiac acceleration to threat vocalizations resulted largely from enhanced sympathetic activity. Although, in this event, one might also expect to see a corresponding decrease in RSA, 
sympathetic and parasympathetic reciprocity is known to break down under certain conditions. This is especially true with marked sympathetic activation, during which vagal discharge may not evidence reciprocal inhibition (Grossman, 1983; Koizumi, Terui, \& Kollai, 1983).

The behavioral, physiological, and psychophysiological findings outlined above are supportive of the conclusion that threat barks, unlike other acoustic stimuli, resulted in the elicitation of an affective or aversive reaction, characterized by sympathetic activation. Although this interpretation is in need of further confirmation, the fact remains that the pattern of evoked cardiac response clearly differentiated among the vocalization stimuli. The selective pattern of cardiac response to threat vocalizations did not appear to be developmentally dependent, at least within the ages of the subjects of this study. Indeed, the youngest chimpanzee (48 hr) displayed the largest acceleratory responses to the threat stimulus. This does not necessarily indicate that the perceptual reactions to threat are constitutionally endowed, because previous studies have found that perceptual learning may occur even prenatally (DeCasper \& Fifer, 1980; DeCasper \& Spence, 1986). Additional evidence, however, suggests the existence of inherent predispositions for the processing of vocal stimuli. Thus, the magnitude of the deceleratory orienting response in the swamp sparrow can reliably distinguish between the conspecific song and that of the song sparrow, even on the very first exposure to these vocalizations (Dooling \& Searcy, 1980). Moreover, although early learning in animals may be critically important in the normal development of vocalization, this learning is often dependent on exposure to species-characteristic vocal patterns, a finding that further supports a constitutional preparedness for the processing of specific vocal signals (Nottebohm, 1984, Nottebohm et al. 1986; Snowdon, 1982). Additional findings suggest an anatomical basis for specialized vocal processing in both humans and primates. Petersen et al. (1984) demonstrated that monkeys evidence lateralized processing of conspecific, but not contraspecific, vocalizations, and Morse et al. (1987) identified lateralized cerebral evoked responses to specific classes of vocal stimuli in primates. In addition, LeMay and Geschwind (1975) and Yeni-Komshian and Benson (1976) reported a lateralized enlargement of cortical areas in apes, which correspond to regions involved in language processes in humans. The results of those studies, together with the present finding of a specific, early developing cardiac response to threat vocalizations, are consistent with the suggestion of a constitutional basis for specialized perceptual processing of vocal signals in primates. Additional work, however, is clearly necessary to specify the relative contributions of learning and constitutional factors to this perceptual phenomenon.

An important question arises as to the specific acoustic features of the threat vocalization that resulted in the observed pattern of cardiac response. The specificity of this response can not be attributed to the gross features of the stimuli, such as intensity, rise time, or envelope duration, because these features were matched among the stimuli. The "frequency code" hypothesis (Bauer, 1987; Morton, 1977; Ohala, 1984) maintains that aggressive, dominant, or threatening vocalizations, across a wide range of species, evidence a lower pitch than do submissive or neutral signals. In accord with this hypothesis, threat barks had a considerably lower frequency composition than did the stress vocalization, and they differed from alarm primarily by an additional low-frequency peak (at approximately $450 \mathrm{~Hz}$ ). Thus, consistent with the frequency-code hypothesis, threat contained a greater preponderance of low frequencies than did other vocalizations. The frequency composition of the noise stimulus, however, was relatively flat from 100 to $3.5 \mathrm{kHz}$ and included the low-frequency components associated with threat. Consequently, the mere appearance of low frequencies in the signal does not appear to account for the differential response to threat. Moreover, threat vocalizations of the orangutan are also characterized by low-frequency components (MacKinnon, 1974), yet these animals did not evidence cardiac acceleration to the chimpanzee threat barks. It is now clear that subtle variations in tonal patterns within a vocal envelope can dramatically alter the communicative significance of primate vocalizations (Seyfarth \& Cheney, 1984). 
In view of these considerations, further studies are clearly necessary to identify the critical differentiating features of the acoustic stimuli.

In summary, psychophysiological methods appear to offer a viable approach to the ontogenetic study of vocal perception in nonhuman primates. Cardiac responses to conspecific vocalizations in chimpanzees, even the neonate, clearly distinguish threat barks from alarm calls, stress screams, and white noise stimuli. The early ontological appearance of this differentiation suggests the existence of a specialized perceptual processing mechanism for vocal stimuli in the chimpanzee. The present results do not clarify the relative contributions of constitutional factors and early learning to the differential patterns of cardiac response. Most of the chimpanzees, however, had minimal exposure to conspecific vocalizations, and this experience was similar to that of the orangutans, which failed to show a differentiated response to threat. Consequently, if learning processes did contribute to the pattern of cardiac response, it seems likely that the chimpanzee may evidence a constitutional preparedness for this learning.

\section{References}

Aslin, R., Pisoni, D., \& Jusczyk, P. (1983). Auditory development and speech perception in infancy. In J. Campos \& M. Haith (Eds.), Mussen's handbook of child psychology: Vol 2. Infancy and developmental psychobiology (pp. 137-156). Somerset, NJ: Wiley.

Bauer, H. R. (1987). The frequency code: Orofacial correlates of fundamental frequency. Phonetica, 44, 173-191.

Berg, W. K., \& Berg, K. M. (1979). Psychophysiological development in infancy. In J. Oslovsky (Ed.), Handbook of infant development (pp. 283-343). New York: Wiley.

Berg, K. M., \& Smith, M. (1983). Behavioral thresholds for tones during infancy. Journal of Experimental Child Psychology, 35, 409-425.

Bemtson, G. G., \& Boysen, S. T. (1984). Cardiac startle and orienting responses in the great apes. Behavioral Neuroscience, 98, 914-918.

Berntson, G. G., \& Boysen, S. T. (1987). Cardiac reflections of attention and preparatory set in a chimpanzee (Pan troglodytes). Psychobiology, 15, 87-92.

Berntson, G. G., Tuber, D. S., Ronca, A. E., \& Bachman, D. S. (1983). The decerebrate human: Associative learning. Experimental Neurology, 81, 77-88.

Bloomfield, P. (1976). Fourier analysis of time series: An introduction. New York: Wiley.

Boysen, S. T., \& Berntson, G. G. (1986). Cardiac correlates of individual recognition in the chimpanzee (Pan troglodytes). Journal of Comparative Psychology, 100, 321-324.

Cheney, D. L., \& Seyfarth, R. M. (1980). Vocal recognition in free-ranging vervet monkeys. Animal Behaviour, 28, 362-367.

Cooley, J. W., \& Tukey, J. W, (1965). An algorithm for the machine computation of complex Fourier Series. Mathematical Computation, 19, 297-301.

Dailey, W., Wigal, S. B., \& Amsel, A. (1986). Effects of photic stimulation on heart rate of infant rats. International Journal of Psychophysiology, 3, 183-204.

DeCasper, A. J., \& Fifer, W. P. (1980). Of human bonding: Newborns prefer their mothers' voices. Science, 208, 1174-1176.

DeCasper, A. J., \& Spence, M. J. (1986). Prenatal maternal speech influences newborns' perception of speech sounds. Infant Behavior and Development, 9, 133-150.

Dennett, D. C. (1983). Intentional systems in cognitive ethology: The "panglossian paradigm" defended. Behavioral and Brain Sciences, 6, 343-390.

Dooling, R., \& Searcy, M. (1980). Early perceptual selectivity in the swamp sparrow. Developmental Psychobiology, 13, 499-506. 
Goldman, D., Giri, P. R., \& O'Brien, S. J. (1987). A molecular phylogeny of the hominoid primates as indicated by two-dimensional protein electrophoresis. Proceedings of the National Academy of Sciences of the United States of America, 84, 3307-3311.

Goodman, M., Braunitzer, G., Stangl, A., \& Schrank, B. (1983). Evidence on human origins from haemoglobins of African apes. Nature, 303, 546-548.

Graham, F. K. (1979). Distinguishing among orienting, defensive, and startle reflexes. In H. D. Kimmel, E. H. van Olst, \& J. F. Orlebeke (Eds.), The orienting reflex in humans (pp. 137-167). Hillsdale; NJ: Erlbaum.

Graham, F. K. (1984). An affair of the heart. In M. G. H. Coles, J. R. Jennings, \& J. A. Stern (Eds.), Psychophysiological perspectives: Festschrift for Beatrice and John Lacey (pp. 171-187). New York: Van Nostrand Reingold.

Graham, F. K., Anthony, B. J., \& Zeigler, B. L. (1983). The orienting response and developmental processes. In D. Siddle (Ed.), Orienting and habituation: Perspectives in human research (pp. 371-430). New York: Wiley.

Green, S. (1975). Communication by a graded vocal system in Japanese monkeys. In L. A. Rosenblum (Ed.), Primate Behavior: Developments infield and laboratory research (Vol. 4, pp. 1-102). New York: Academic Press.

Grossman, P. (1983). Respiration, stress and cardiovascular function. Psychophysiology, 20, 284-300.

Haroutunian, V., \& Campbell, B. A. (1982). Neural control of the heart-rate-orienting response in preweanling rats. Behavioral and Neural Biology, 36, 24-39.

Heslegrave, R. J., Ogilvie, J. C., \& Furedy, J. J. (1979). Measuring baseline-treatment differences in heart rate variability: Variance versus successive difference mean square and beats per minute versus interbeat intervals. Psychophysiology, 16, 151-157.

Koizumi, K., Terui, N., \& Kollai, M. (1983). Neural control of the heart: Significance of double innervation re-examined. Journal of the Autonomic Nervous System, 7, 279-294.

Kuhl, P. K. (1987a). Perception of speech and sound in early infancy. In P. Salapatek \& L. Cohen (Eds.), Handbook of infant perception: From perception to cognition (Vol. 2, pp. 274-382). New York: Academic Press.

Kuhl, P. K. (1987b). The special-mechanisms debate in speech research: Categorization tests on animals and infants. In S. Hamad (Ed.), Categorical perception for speech (pp. 355-386). London: Cambridge University Press.

Larson, S. K., \& Forges, S. W. (1982). The ontogeny of heart period patterning in the rat. Developmental Psychobiology, 15, 519-528.

LeMay, M., \& Geschwind, N. (1975). Hemispheric differences in the brains of the great apes. Brain, Behavior and Evolution, 11, 48-52.

Liberman, A. M., Cooper, F. S., Shankweiler, D. P., \& Studdert-Kennedy, M. (1967). Perception of the speech code. Psychological Review, 74, 431-461.

MacKinnon, J. (1974). The behavior and ecology of the orangutan (Pongo pygmaeus). Animal Behaviour, 22, 3-74.

Marler, P., \& Tenaza, R. (1977). Signaling behavior of apes with special reference to vocalization. In T. A. Sebeok (Ed.), How animals communicate (pp. 965-1032). Bloomington: Indiana University Press.

McCabe, P. M., Yongue, B. G., Ackless, P. K., \& Forges, S. W. (1985). Changes in heart period, heartperiod variability, and a spectral analysis estimate of respiratory sinus arrhythmia in response to pharmacological manipulations of the baroreceptor reflex in cats. Psychophysiology, 22, 195-203.

Molfese, D. L. (1987). Electrophysiological indices of categorical perception for speech. In S. Hamad (Ed.), Categorical perception for speech (pp. 421-443). London: Cambridge University Press.

Morrongiello, B. A., \& Clifton, R. K. (1984). Effects of sound frequency on behavioral and cardiac orienting in newborn and fivemonth-old infants. Journal of Experimental Child Psychology, 38, 429-446. 
Morse, P. A., Molfese, D., Laughlin, N. K., Linnville, S., \& Wetzel, F. (1987). Categorical perception for voicing contrasts in normal and lead-treated rhesus monkeys: Electrophysiological indices. Brain and Language, 30, 63-80.

Morton, E. S. (1977). On the occurrence and significance of motivational/structural rules in some bird and mammal sounds. American Naturalist, 111, 855-869.

Newman, J. D., \& Symmes, D. (1982). The ontogeny of vocal communication in monkeys. In C. T. Snowdon, C. H. Brown, \& M. R. Peterson (Eds.), Primate communication (pp. 239-248). London: Cambridge University Press.

Nottebohm, F. (1984). Birdsong as a model in which to study brain processes related to learning. Condor, 86, 227-236.

Nottebohm, F., Nottebohm, M. E., \& Crane, L. (1986). Development and seasonal changes in canary song and their relation to changes in the anatomy of song-control nuclei. Behavioral and Neural Biology, 46, 445-471.

Obrist, P. A. (1982). Cardiovascularpsychophysiology. A perspective. New York: Plenum Press.

Obrist, P. A., Wood, D. M., \& Perez-Reyes, M. (1965). Heart rate during conditioning in humans: Effects of UCS intensity, vagal blockade, and adrenergic block of vasomotor activity. Journal of Experimental Psychology, 70, 32-42.

Ohala, J. J. (1984). An ethological perspective on cross-language utilization of Fo in the voice. Phonetica, 41, 1-16. Petersen, M. R. (1982). The perception of species-specific vocalizations by primates: A conceptual framework. In C. T. Snowdon, C. H. Brown, \& M. R. Peterson (Eds.), Primate communication (pp. 171-211). London: Cambridge University Press.

Petersen, M. R., Zoloth, S. T., Beecher, M. D., Green, S., Marler, P. R., Moody, D. B., \& Stebbins, W. C. (1984). Neural lateralization of vocalizations by Japanese macaques: Communicative significance is more important than acoustic structure. Behavioral Neuroscience, 98, 779-790.

Pisoni, D. B. (1987). Auditory perception of complex sounds: Comparisons of speech vs. nonspeech signals. In W. A. Yost \& C. S. Watson (Eds.), Auditory processing of complex sounds (pp. 247256). Hillsdale, NJ: Erlbaum.

Pohl, P. (1983). Central auditory processing: V. Ear advantages for acoustic stimuli in baboons. Brain and Language, 20, 44-53.

Porges, S. W., McCabe, P. M., \& Yongue, B. G. (1982). Respiratory heart rate interactions: Psychophysiological implications for pathophysiology and behavior. In J. T. Cacioppo \& R. E. Petty (Eds.), Perspectives in cardiovascular psychophysiology (pp. 223-264). New York: Guilford Press.

Seyfarth, R. M., \& Cheney, D. L. (1984). The natural vocalizations of non-human primates. Trends in Neuroscience, 7, 66-73.

Snowdon, C. T. (1982). Linguistic and psycholinguistic approaches to primate communication. In C. T. Snowdon, C. H. Brown, \& M. R. Peterson (Eds.), Primate communication (pp. 212-238). London: Cambridge University Press.

Snowdon, C. T., \& Cleveland, J. (1980). Individual recognition of contact calls by pygmy marmosets. Animal Behaviour, 28, 717-727.

Sokolov, Y. N. (1963). Perception and the conditioned reflex. New York: Pergamon.

Spinks, J. A., \& Siddle, D. (1983). The functional significance of the orienting response. In D. Siddle (Ed.), Orienting and habituation: Perspectives in human research (pp. 237-313). New York: Wiley.

Trehub, S. E. (1987). Infants' perception of musical patterns. Perception and Psychophysics, 41, 635-641.

Turpin, G. (1983). Unconditioned reflexes and the autonomic nervous system. In D. Siddle (Ed.), Orienting and habituation: Perspectives in human research (pp. 1-69). New York: Wiley.

Turpin, G. (1986). Effects of stimulus intensity on autonomic responding: The problem of differentiating orienting and defense reflexes. Psychophysiology, 23, 1-14. 
van Lawick-Goodall, J. (1968). The behavior of free-living chimpanzees of the Gombe Stream Reserve. Animal Behaviour Monpgraph, 1, 161-311.

Weisbard, C., \& Graham, F. K. (1971). Heart-rate change as a component of the orienting response of monkeys. Journal of Comparative and Physiological Psychology, 76, 74-83.

Yeni-Komshian, G., \& Benson, D. (1976). Anatomical study of cerebral asymmetry in temporal lobe of humans, chimpanzees, and rhesus monkeys. Science, 192, 387-389.

Yongue, B. G., McCabe, P. M., Forges, S. W., Rivera, M., Kelley, S. L., \& Ackles, P. KL. (1982). The effects of pharmacological manipulations that influence vagal control of the heart on heart period, heart-period variability and respiration in rats. Psychophysiology, 19, 426-432. 